\title{
Research in Autonomous Driving - A Historic Bibliometric View of the Research Development in Autonomous Driving
}

\author{
${ }^{1}$ Sandra Boric, ${ }^{2}$ Edgar Schiebel, ${ }^{3}$ Christian Schlögl, ${ }^{4}$ Michaela Hildebrandt, ${ }^{5}$ Christina Hofer, \\ ${ }^{6}$ Doris M. Macht \\ ${ }^{1}$ Insitute of Marketing, University of Graz, Graz, Austria \\ ${ }^{2}$ AIT Austrian Institute of Technology $\mathrm{GmbH}$, Vienna, Austria \\ ${ }^{3}$ Institute of Operations and Information Systems, University of Graz, Graz, Austria \\ 4,5,6 University of Graz, Graz, Austria
}

\begin{abstract}
Autonomous driving has become an increasingly relevant issue for policymakers, the industry, service providers, infrastructure companies, and science. This study shows how bibliometrics can be used to identify the major technological aspects of an emerging research field such as autonomous driving. We examine the most influential publications and identify research fronts of scientific activities until 2017 based on a bibliometric literature analysis. Using the science mapping approach, publications in the research field of autonomous driving were retrieved from Web of Science and then structured using the bibliometric software BibTechMon by the AIT (Austrian Institute of Technology). At the time of our analysis, we identified four research fronts in the field of autonomous driving: (I) Autonomous Vehicles and Infrastructure, (II) Driver Assistance Systems, (III) Autonomous Mobile Robots, and (IV) IntraFace, i.e., automated facial image analysis. Researchers were working extensively on technologies that support the navigation and collection of data. Our analysis indicates that research was moving towards autonomous navigation and infrastructure in the urban environment. A noticeable number of publications focused on technologies for environment detection in automated vehicles. Still, research pointed at the technological challenges to make automated driving safe.
\end{abstract}

Keywords: Science Mapping, Autonomous Driving, Research Fronts, Bibliographic Coupling, Technology Management, Business Intelligence, Technology Watch

\section{Introduction}

An early identification of new technologies is essential for the development of corporate strategies in which upcoming trends should be considered. The early recognition of new technologies aims at the identification of upcoming developments in relevant technological areas and at evidence-based technology-related management decisions. Therefore, all information that might influence the (future) corporate environment should be gathered and provided as early as possible (Schuh et al., 2010, p. 15). If a corporate institution is taken by surprise due to upcoming technological changes, its competitive position could be jeopardized. Yet, the rapid growth of the world's knowledge is a challenge for the early identification of new technologies. Since human beings are not able to process the volume of all available data by themselves, organisations need to acquire competencies in data management for business intelligence in order to stay competitive. The high complexity - as well as the lack of transparency - is, however, not to be underestimated (Wellensiek et al., 2010, p. 89ff.).

Progress in research and technology development concerning autonomous driving is of interest particularly to manufacturers and suppliers of autonomous vehicles. Early technology detection 
plays an important role for these companies in order to stay informed about new technologies, research priorities, and trends in a timely manner, as well as to take advantage of certain opportunities and to minimize risks (Krystek, 2007, p. 50).

Autonomous driving is considered a megatrend for the mobility of the future, and it is currently a hot topic in the media, politics, and economy. Its development goes hand in hand with emobility and alternative mobility concepts such as car sharing (Krimmel \& Ersoy, 2017, p. 914). It is a key driver for technological innovations in the automotive industry. As its technical development is progressing in a fast manner, it is likely to change the automotive industry fundamentally in the upcoming few years (Cacilo et al., 2015, p. 2).

The research field of autonomous driving is an interdisciplinary topic. It requires intensive cooperation between car manufacturers, suppliers, IT companies, and energy and infrastructure suppliers (Barthelmes et al., 2017, p. 6). This also means that the already highly competitive international car market is becoming increasingly attractive for newcomers. Compared to traditional manufacturers from Europe and America, manufacturers from East Asia (i.e., Japan, Korea, and China) have entered the market in the last couple of years. In addition, the market is becoming increasingly attractive to technology players such as Alphabet Inc. (formerly Google) which is quite active in the market via its subsidiary Waymo. Furthermore, electrification leads to the emergence of new competitors for traditional automakers, e.g., Tesla (Bardt, 2016, p. 776).

Autonomous driving can be defined as having five stages of automation which vary in the possibility to intervene.

The first stage is the driver-only stage at which the driver executes the longitudinal as well as the transverse guidance throughout the entire ride (BMVI - Automatisiertes Und Vernetztes Fahren, n.d.). The second stage is the assisting stage which generally functions identically to the driver-only stage. The only difference between these two stages is that, within certain limits, the assisting stage enables the system to carry out either the longitudinal or the transverse guidance while the driver executes all other tasks. One example is the parking assistant, where the driver still controls the longitudinal guidance while the assistant takes over the transverse guidance. The third stage is the partially automated driving stage at which the longitudinal and transverse guidance is executed by the system for a certain period of time or in a certain situation. An example is the so-called highway assistant system. The fourth stage is the highly automated driving stage. In contrast to the third stage, at this fourth stage, the driver does not have to permanently monitor the system. The highest stage is the full automation stage at which the vehicle drives without human control. This means that the system executes the longitudinal and transverse guidance entirely on its own in a defined application case such as the highway pilot (Gasser et al., 2012, p. 9).

In addition to numerous new application possibilities and opportunities offered by this emerging technology, there are still a multitude of open questions and challenges regarding autonomous vehicles. As long as those are not resolved, autonomous vehicles will not be ready for serial production. Besides technological challenges, actors in these systems must also deal with legal, ethical, social, economic, and ecological issues. The technological issues usually have to be solved first, though (Handelsblatt, 2018; Schreurs \& Steuwer, 2016, p. 149).

Safety issues, privacy issues, and issues regarding the trust of customers are the biggest hurdles that autonomous driving has to overcome (Watzenig \& Horn, 2016, p. 26). About $94 \%$ of car accidents can - at least partially - be attributed to driving errors (Kyriakidis et al., 2015, p. 127). Safety threats include the manipulation of the steering wheel and brakes as well as the distraction of the driver (Langheim, 2015, p. 14). Customers need to be aware of potential security holes in a vehicle. They also need to understand how their protection works since they will not be willing to pay for more security as long as they do not understand the derived benefits. Aside from consumer trust, the security of customer data is of vital importance. The 
minimisation of customer data collection to a bare minimum can increase customer trust (Watzenig \& Horn, 2016, p. 23).

The first fatal accident caused by a self-driving test car occurred when a vehicle belonging to the American transportation company Uber hit a woman in the US state of Arizona. This accident showed that the technology used in autonomous vehicles was not yet able to fully grasp its environment (Handelsblatt, 2018).

The ethical question regarding the correct decision made in dangerous situations is a sub-area of autonomous driving. Autonomy means that the laws to which the vehicle is sub-ordinated must always spring from the will of a rational being. This will is regarded as general legislative (Feil, 1987, p. 45). Software still cannot assess human behaviour, thus predefined rules are required to make decisions (Krieger-Lamina, 2016, p. 60). The combination of this legislative and self-determination poses a great challenge. Since there is no ethically correct answer to the implementation of programmed action guidelines for autonomous vehicles, said implementation still remains subjective (Brownsword et al., 2017, p. 612).

A social benefit from autonomous driving arises from the enablement of independent travel for people with reduced mobility (Matthaei et al., 2015, p. 1140). Another application area of autonomous driving is car sharing (e.g., autonomous taxis) which is a result of the shift from ownership to rental models. Besides private transport, public transport is another potential application area for autonomous vehicles (Krieger-Lamina, 2016, p. 71). In particular, autonomous driving allows for an individualization of public transport (Maurer et al., 2015, p. 147 ) so that fixed route plans can be supplemented by flexible route plans. Bus routes could evolve depending on the selected time and destination of the target customers (Maurer et al., 2015, p. 189).

The aim of this paper is to identify the research status of autonomous driving until 2017 in order to build a basis for an early identification of relevant issues in this technological field. Therefore, research literature regarding autonomous driving has been investigated by applying the bibliometric method of science mapping which is described in the following.

\section{Methodology and Data}

The following is a description of the method of science mapping, of the mapping tool BibTechMon, and of the data source used in this study.

There are various methods to facilitate the identification of new technological developments at an early stage. One of those methods is science mapping which was used in this study. Science mapping is a bibliometric method that structures disciplines, scientific domains, or significant research fronts of a research area in a conceptual and intellectual way. Several procedures and applications have already been developed to conduct suitable science mapping analyses (Cobo et al., 2011, p. 1382). Science mapping detects and correlates a high amount of data. We used data of high quality, and our applied science mapping tool for data processing (i.e., BibTechMon) was adequate for achieving reasonable results according to Börner et al. (2015, p. 15).

Science mapping analyses can be performed in different ways. Some common approaches are the co-word analysis, the co-author analysis, and bibliographic coupling.

The co-word analysis is characterized by the co-occurrence of keywords in documents. As soon as two or more keywords appear in the same documents, a connection between these documents can be derived. The more often keywords are co-occurring, the stronger the relation is between documents (Callon et al., 1983; Chen et al., 2016, p. 548; Fischler \& Bolles, 1981).

The co-author analysis investigates authors who jointly publish papers. This form of documented science communication makes international collaboration measurable. Most bibliometric studies of this kind are concerned with the share of internationally co-authored papers and their impact on national and international research. This kind of analysis furthermore allows for an analysis 
and mapping of the structure of collaboration links. For example, De Lange \& Glänzel (1997) introduced the multilateral collaboration index to measure the change of multi-national collaboration based on international co-publication links.

The method of bibliographic coupling was introduced by Kessler (1963). It aims to examine the congruent reference lists of two documents. Two documents are bibliographically coupled if they have at least one reference in common (Ahlgren \& Jarneving, 2008, p. 274; Kessler, 1963). The more common references two publications have, the more similar they are regarded to be.

In our study, the science mapping exercise was performed using a bibliometric software called BibTechMon (AIT Austrian Institute of Technology $\mathrm{GmbH}, 2018$ ). Based on complex mathematical and mechanical models, BibTechMon assesses bibliometric data and conducts a co-frequency analysis. Derived from the idea of co-word analysis, the methodology looks at the co-occurrence of items for similarity and uses an iteration model for the calculation of similar objects. The iteration model is used for the positioning of objects in a two-dimensional space based on their similarities to each other (Kopcsa \& Schiebel, 1998).

A major feature of BibTechMon is that it enables the identification and visualization of research fronts - which is the focus of this paper. An important influencer of the definition of "research fronts" is Price (1965) who describes them as an accumulation of documents and their authors in one research field. Since publications show the most mutual citations, each accumulation distinguishes itself from the rest. Publications within the same research front show a high number of common content (Lietz, 2013, p. 357; Price, 1965). The higher the number of common references, the stronger the relation.

The keywords, organisations, and abstracts of the publications in a research front form the basis for finding the topic of each research front. The topics cannot be distinguished clearly by merely looking at the keywords, because often times the same keywords occur in different contexts. Therefore, the titles, abstracts, and content of the papers as well as their affiliated organisations and research departments must also be taken into consideration.

All data for this study was retrieved from Web of Science (abbreviated WoS) at two different dates. When searching for the exact wording "autonomous driving" in the topic-field of WoS (which considers the title, abstract and keywords), 1,202 matching results were found for the time span of 2010 to 2017 . The retrieval date was November $23^{\text {rd }}, 2017$. This data was used for the identification of research fronts in autonomous driving in 2017. For the representation of the time series 2000 to 2017, we conducted a second retrieval by a later date, i.e., December $31^{\text {st }}, 2017$. A total of 1,445 hits were found in the course of this second retrieval.

All 1,202 documents (i.e., 2010 to 2017) on autonomous driving obtained from the results list were downloaded from WoS and imported into the bibliometric software BibTechMon. In BibTechMon, the data was processed and analysed by creating and visualising networks based on the similarities of different objects. Similar documents were clustered to research fronts for the time period of 2010 to 2017 on autonomous driving using bibliographic coupling. BibTechMon generates a two-dimensional network in which important relations are shown as agglomerations of similar publications. Using the processed data of BibTechMon, it is furthermore possible to create a landscape in $2 \mathrm{D}$ and $3 \mathrm{D}$ surface maps. These maps visualize research fronts as red areas in a heat map. The 3D version further visualizes peaks of local distributions of similar documents. The $x$ and $y$ axis are local coordinates, and the $z$ axis represents the local number of similar documents - each weighted with the Jaccard index of the number of common references. ${ }^{1}$ This way, red or "hot" areas indicate a high research activity in a certain subfield of very similar published articles.

\footnotetext{
${ }^{1}$ The Jaccard index is a similarity measure of two documents. It is normalized between 0 and 1 by taking the quotient of the number of common references divided by the sum of all references of the two documents minus the number of common references.
} 


\section{Findings}

Based on the analyses and results obtained via WoS and BibTechMon, several frequency distributions as well as main research areas in the field of autonomous driving are presented in this chapter. First, an overview of research related to autonomous driving is provided by applying the WoS analyse results-tool on the obtained data set from 2010 to 2017 with 1,445 publications. Afterwards, four research fronts obtained using BibTechMon are presented.

Among others, the WoS analyse results-tool performs analyses by the number of publications per year (i.e., time series), per country/region, per funding agency, and per organisation. Figure 1 visualizes the absolute number of annual publications indexed in WoS between 2000 and 2017. It shows that particularly from 2013 onwards, autonomous driving has experienced a high rise in the number of published research papers. In absolute numbers, the highest increase occurred between 2016 and 2017 (+111 publications, from 283 to 394 in total) and between 2014 and 2015 (+100 publications, from 138 to 238). In relative numbers, the highest increase occurred between 2014 and 2015 (+72\%) and between 2013 and 2014 (+68\%, from 82 to 138 papers). This tremendous growth in the research output underlines the high awareness and interest of the scientific community in autonomous driving.

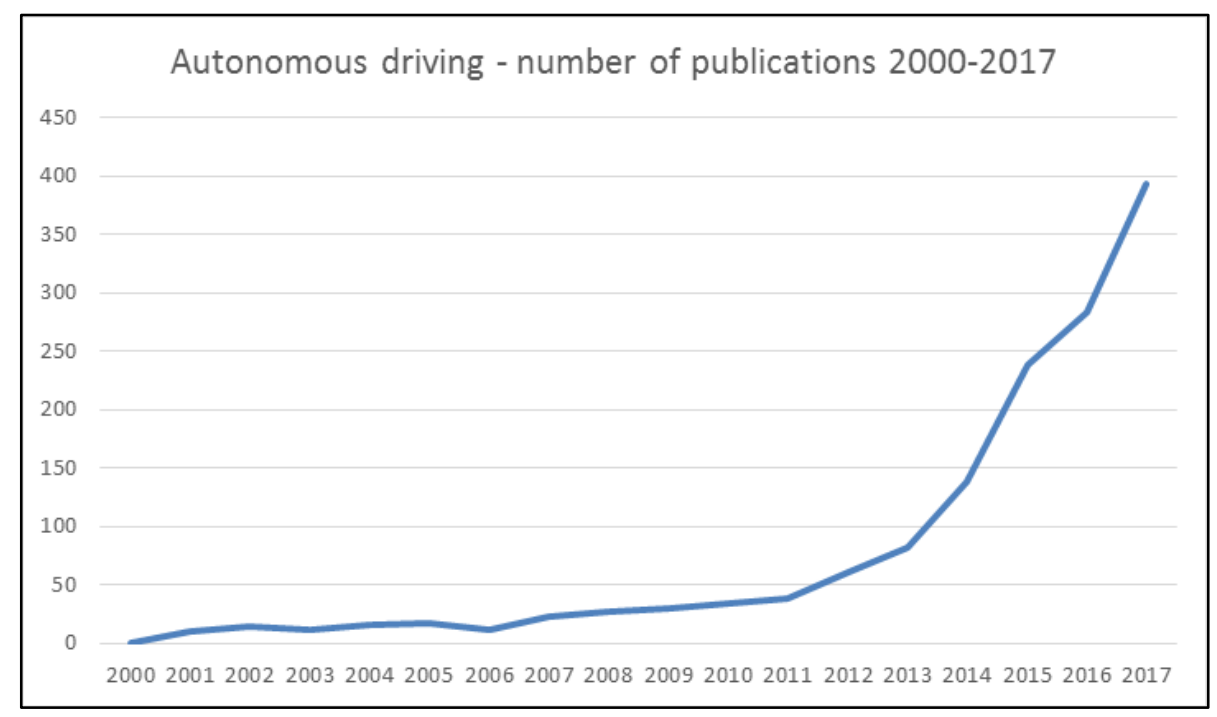

Figure 1: Number of publications on autonomous driving from 2000 to 2017 in WoS. Created by the WoS analyse results-tool using 1,445 publications retrieved on December 31 2017.

$24.9 \%$ of the 1,445 publications (i.e., 360 papers) retrieved from WoS originate from Germany, followed by the USA with $22.4 \%$ (i.e., 324 papers) and by the People's Republic of China with $12.2 \%$ (i.e., 176 papers). Japan ranks fourth with $8.8 \%$ (i.e., 127 papers), and South Korea ranks fifth with $8.7 \%$ (i.e., 125 papers).

It is hardly surprising that Germany is leading the top five due to the great importance of the automotive industry in this country. In 2017, German companies such as Daimler (Daimler, 2021; Fraedrich et al., 2014) and Volkswagen (Thrun et al., 2006) were contributing the most to Germany's position in the research field of autonomous driving. According to our results, Daimler even ranks second among all organisations with 37 out of 1,445 publications linked to researchers affiliated with Daimler. Besides Daimler, another automotive company publishing in the field of autonomous driving is the German company Robert Bosch Ltd. which ranks $14^{\text {th }}$ in our results by organisations with a total of 17 publications. The Japanese Toyota Technological Institute, e.g., ranks $17^{\text {th }}$ by organisation with a total of 13 publications. 
Since national funding of technology reflects the efforts and national strategies to promote technologies, it also makes sense to consider the ranking by funding agencies. Our ranking by funding agencies is led by the National Natural Science Foundation of China with 42 publications, followed by the National Science Foundation of the USA with 13 publications.

In the following, our identified research fronts are presented. To identify research fronts on autonomous driving, all 1,202 publications retrieved from WoS on November 23rd, 2017 were imported into BibTechMon which represents the research fronts as accumulations (which are visualised as peaks). As can be seen in Figure 2, BibTechMon has identified four main research fronts: (I) Autonomous Vehicles and Infrastructure, (II) Driver Assistance Systems, (III) Autonomous Mobile Robots, and (IV) IntraFace. As already mentioned in the methodology section, the keywords, organisations, titles, and abstracts were considered by BibTechMon when naming the research fronts. The following is a detailed description of the four research fronts.

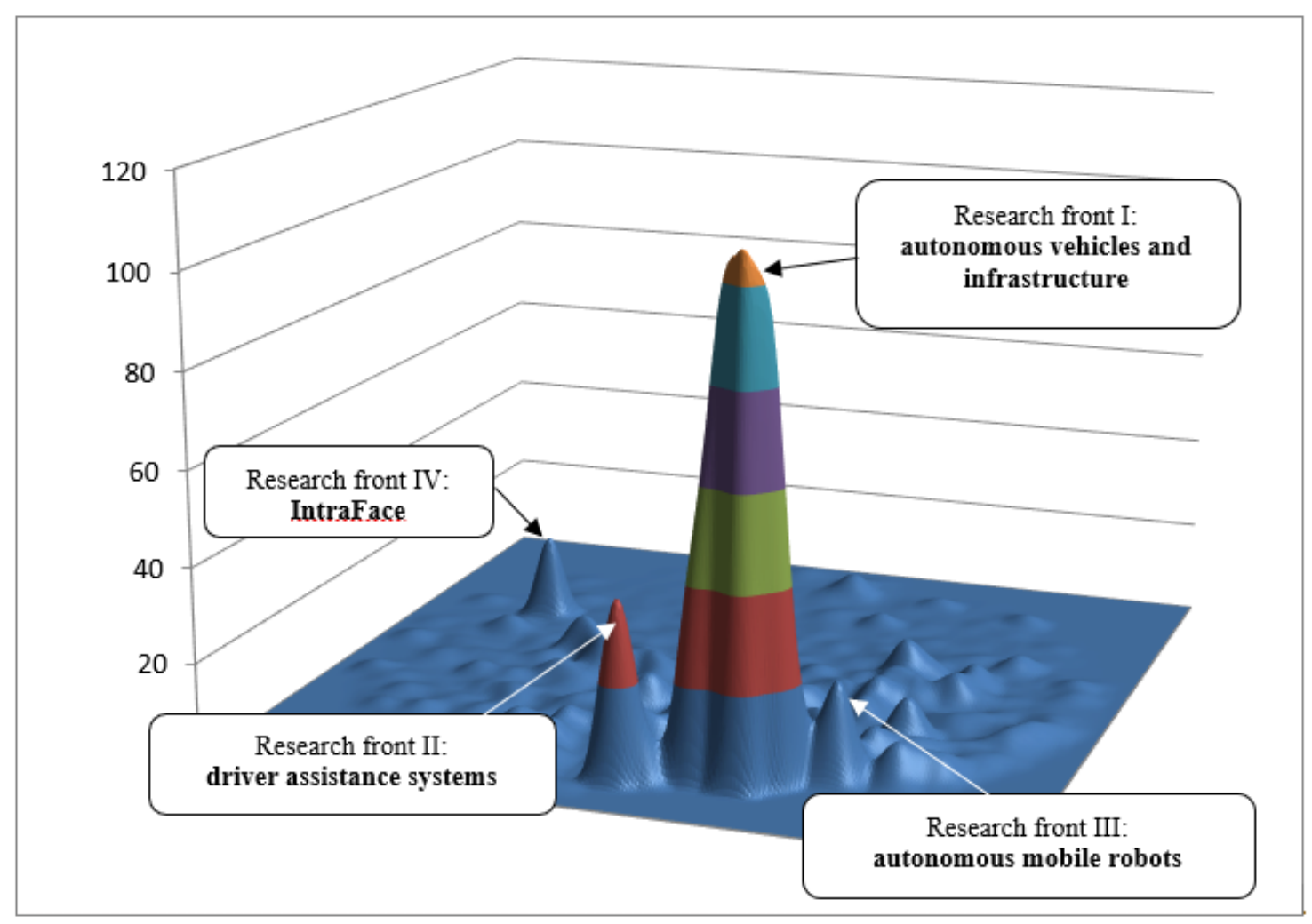

Figure 2: Four research fronts identified in BibTechMon for autonomous driving. The figure shows an agglomeration of the local number of bibliographically coupled similar publications weighted by the Jaccard similarity (sample size: 1,202 publications).

\subsection{Research Front (I): Autonomous Vehicles and Infrastructure}

The first research front (I) Autonomous Vehicles and Infrastructure is the largest in the number of publications. The strong connection to the research field autonomous driving is expressed in that "autonomous car" is the most frequent keyword. Additionally, the position of an adequate infrastructure for autonomous driving is stressed by keywords such as "road modelling" or "road map".

When examining the most frequently publishing research organisations in this research front, a clear tendency towards technical, electronic, and robotic departments can be identified. This suggests that the research of autonomous driving is still in the stage of technological development, with technical issues and infrastructure issues arising. A further interesting finding is that nearly all of the top ten organisations are universities (see Table 1). Except for the 
Carnegie Mellon University in Pittsburgh in the US with six publications, most of them have published only a few papers. Also, the contents of the abstracts of the latest publications exhibit a focus on the development of autonomous vehicles, road construction, and geographic maps.

\begin{tabular}{ll}
\hline Organisation & Country \\
\hline 1. Carnegie Mellon University & USA \\
2. University of the Federal Armed Forces in Munich & Germany \\
3. National University of Singapore & Singapore \\
4. Electronics and Telecommunications Research Institute & South Korea \\
5. General Motors Warren Research \& Development Center & USA \\
6. Hanyang University & South Korea \\
7. Massachusetts Institute of Technology & USA \\
8. National University of Defense Technology & China \\
9. Singapore-MIT Alliance for Research and Technology & Singapore \\
10. University of California, Berkeley & USA \\
\hline
\end{tabular}

Table 1: Top 10 organisations by number of publications in research front (I) Autonomous Vehicles and Infrastructure

The most frequently cited article in research front (I) and thus a very influential article is titled "Autonomous Driving in Urban Environments: Boss and the Urban Challenge" by Urmson et al. (2008), published in August 2008 in the Journal of Field Robotics. In research front (I), it has been cited 92 times, while it has been cited 98 times in all 1,202 publications. This article introduces the self-driving car "Boss" which is equipped with an on-board sensor for vehicles or obstacle traction. The vehicle's environment has to be tracked to make autonomous driving possible in different situations (Urmson et al., 2008, p. 425).

Most of the top-cited publications in research front (I) were published in the aforementioned Journal of Field Robotics. Four of the highest cited articles were even published in the same journal issue. One of those four articles is titled "Junior: The Stanford Entry in the Urban Challenge" by Montemerlo et al. (2008). This article also deals with an autonomously driving robotic vehicle that can search for routes independently. It can interact with other road users, and it possesses driving skills such as 180-degree turning and parking (Montemerlo et al., 2008, p. 569).

Another relevant and frequently cited article with the title "Stanley: The robot that won the DARPA Grand Challenge" was also published in the Journal of Field Robotics in 2006. Stanley is described as a robot equipped with artificial intelligence. It can independently drive in the desert at extreme speed. To operate independently, the robot is equipped with artificial intelligence. The article specifies the main components of its architecture and discusses the results of the DAPRA Grand Challenge which Stanley won in 2005 (Thrun et al., 2006, pp. 661-662).

A journal that contains several of the most cited articles is the IEEE Intelligent Transportation System Magazine. Its article "Making Bertha drive - An autonomous journey on a historic route" was published in 2014. It deals with a car from the Mercedes-Benz S-Class S500 Intelligent Drive, which has travelled the route from Mannheim to Pforzheim in Germany autonomously (Ziegler et al., 2014, p. 8). Another of its articles titled "Towards fully autonomous driving: systems and algorithms" was published in 2011. It is about the robotic car Junior, which was already introduced in the Journal of Field Robotics in 2008, and it is dedicated to the software behind this autonomous vehicle (Levinson et al., 2011, p. 163).

In summary, the most frequently cited publications of research front (I) deal with various autonomous vehicles and the software they use. This includes route planning and infrastructure. 
The previously identified keywords can be confirmed by the cited publications and reflect exactly the expected content. In addition, IEEE Intelligent Transportation System Magazine and the Journal of Field Robotics provide the most relevant content. Table 2 lists the ten latest publications in research front (I).

\begin{tabular}{|c|c|c|c|c|}
\hline Author(s) & Title & Journal name & Publ. Year & Country \\
\hline $\begin{array}{l}\text { Darweesh, Hatem; } \\
\text { et al. }\end{array}$ & $\begin{array}{l}\text { Open Source Integrated Planner for Autonomous } \\
\text { Navigation in Highly Dynamic Environments }\end{array}$ & $\begin{array}{l}\text { Journal of Robotics } \\
\text { and Mechatronics }\end{array}$ & 2017 & Japan \\
\hline $\begin{array}{l}\text { Huang, Rulin; et } \\
\text { al. }\end{array}$ & $\begin{array}{l}\text { Intent-Estimation- and Motion-Model-Based } \\
\text { Collision Avoidance Method for Autonomous } \\
\text { Vehicles in Urban Environments }\end{array}$ & Applied Sciences & 2017 & China \\
\hline Cao, Peng; et al. & $\begin{array}{l}\text { An optimal mandatory lane change decision model } \\
\text { for autonomous vehicles in urban arterials }\end{array}$ & $\begin{array}{l}\text { Journal of Intelligent } \\
\text { Transportation } \\
\text { Systems }\end{array}$ & 2017 & $\begin{array}{l}\text { China, } \\
\text { Japan }\end{array}$ \\
\hline $\begin{array}{l}\text { Lüttel, Thorsten; } \\
\text { et al. }\end{array}$ & $\begin{array}{l}\text { Autonomous driving functions reducing the driver's } \\
\text { cognitive load in off-road scenarios }\end{array}$ & $\begin{array}{c}\text { AT- } \\
\text { Automatisierungstechn } \\
\text { ik }\end{array}$ & 2017 & Germany \\
\hline $\begin{array}{l}\text { Lee, Honggu; et } \\
\text { al. }\end{array}$ & $\begin{array}{l}\text { An incremental nonparametric Bayesian clustering- } \\
\text { based traversable region detection method }\end{array}$ & Autonomous Robots & 2017 & $\begin{array}{l}\text { South } \\
\text { Korea }\end{array}$ \\
\hline $\begin{array}{l}\text { Gwon, Gi-Poong; } \\
\text { et al. }\end{array}$ & $\begin{array}{l}\text { Generation of a Precise and Efficient Lane-Level } \\
\text { Road Map for Intelligent Vehicle Systems }\end{array}$ & $\begin{array}{l}\text { IEEE Transactions on } \\
\text { Vehicular Technology }\end{array}$ & 2017 & $\begin{array}{l}\text { South } \\
\text { Korea }\end{array}$ \\
\hline Jo, Kichun; et al. & $\begin{array}{l}\text { Construction process of a three-dimensional } \\
\text { roadway geometry map for autonomous driving }\end{array}$ & $\begin{array}{l}\text { Proceedings of the } \\
\text { Institution of } \\
\text { Mechanical Engineers, } \\
\text { Part D: Journal of } \\
\text { Automobile } \\
\text { Engineering }\end{array}$ & 2017 & $\begin{array}{l}\text { France, } \\
\text { South } \\
\text { Korea }\end{array}$ \\
\hline $\begin{array}{l}\text { Galceran, Enric; } \\
\text { et al. }\end{array}$ & $\begin{array}{l}\text { Multipolicy decision-making for autonomous } \\
\text { driving via changepoint-based behavior prediction: } \\
\text { Theory and experiment }\end{array}$ & Autonomous Robots & 2017 & $\begin{array}{l}\text { USA, } \\
\text { Switzerland }\end{array}$ \\
\hline $\begin{array}{l}\text { Zhang, Shuai; et } \\
\text { al. }\end{array}$ & $\begin{array}{l}\text { A Semantic Model for Information Sharing in } \\
\text { Autonomous Vehicle Systems }\end{array}$ & $\begin{array}{c}\text { 2017 IEEE 11th } \\
\text { International } \\
\text { Conference on } \\
\text { Semantic Computing } \\
\text { (ICSC) }\end{array}$ & 2017 & USA \\
\hline Yin, Huilin; et al. & $\begin{array}{l}\text { Spherical Coordinates Based Methods of Ground } \\
\text { Extraction and Objects Segmentation Using 3-D } \\
\text { LiDAR Sensor }\end{array}$ & $\begin{array}{l}\text { IEEE Intelligent } \\
\text { Transportation } \\
\text { Systems Magazine }\end{array}$ & 2016 & China \\
\hline
\end{tabular}

Table 2: Latest publications until 2017 in research front (I) Autonomous Vehicles and Infrastructure

Many publications in Table 2 focus on road maps and planners. The latest article "Open source integrated planner for autonomous navigation in highly dynamic environments" introduces an open source planner named "OpenPlanner", which generates paths dynamically to navigate through dynamic environments (Darweesh et al., 2017, p. 668). The article titled "Construction process of a three-dimensional roadway geometry map for autonomous driving" deals with a 3D roadway geometry map. Post-processing and three-dimensional roadway geometry modelling algorithms are the focus of the article (Jo et al., 2017, p. 1414). Another article deals with a precise and efficient lane-level road-map generation system. A map was constructed by using accurate 3D road geometry data, which were collected with a mobile three-dimensional laser scanner (Gwon et al., 2017, p. 4517). Besides this article, two other articles listed in Table 2 also deal with road lanes and optimal change point detection. One of them introduces a decision model for changing lanes. Its authors examine the regulation of an instruction for the optimal position for lane changing (Cao et al., 2017, p. 271). By means of Bayesian change point detection, another publication reports on multi-policy decision making for autonomous driving (Galceran et al., 2017, p. 1367). Just like in the previous paper, a three-dimensional sensor system is used to extract ground points and non-ground objects (Yin et al., 2016, p. 61). 
Collision avoidance plays another important role in urban environment. Therefore, a method is presented that addresses different disadvantages of false detection rates that lead to collision. The paper argues that the average collision detection distance as well as the accuracy on straight roads and winding roads could be improved (Huang et al., 2017, p. 457).

At present, researchers are working extensively on technologies and maps that help to navigate, to collect data, and to figure out the optimal change point detection. Three of the ten latest publications in 2017 used three-dimensional technologies for their methods (Gwon et al., 2017; Jo et al., 2017; Yin et al., 2016). Compared to the previously described highest cited publications that concentrated on specific robotic autonomous vehicles, the research activities are moving towards autonomous navigation and infrastructure in the urban environment. This is necessary in order to integrate autonomous vehicles for public and private use into the infrastructure of cities. It requires a combination of different technologies as described above.

Most of the publications from 2017 are linked to South Korea, China, and Japan. They deal extensively with the topic of lane change, driving strategy, and cartography for autonomous vehicles in urban areas.

\subsection{Research Front (II): Driver Assistance Systems}

The second research front (II) Driver Assistance Systems deals, as its name suggests, with the topic of driver assistance systems. Figure 2 shows that this research front is the second largest in terms of the number of publications weighted by their similarity. Figure 2 also shows that research front (II) is located to the left of research front (I). Therefore, cited references of articles assigned to the second identified topic (i.e., driver assistance systems) also have a strong connection to the first research front.

The keyword with the highest relevance in this research front is "backward driving", which has a clear relation to the name of this research front. Further keywords like "self-learning-classifier" are associated with driver assistance systems, as well.

Table 3 shows that, just like in research front (I), the research organisations in research front (II) are distributed all over the world. However, European universities have a higher presence here. Besides the USA and Asia, universities from Italy, Germany, Hungary, and England rank among the top ten research organisations measured by the number of publications. Among them, there is only one automotive company: Mitsubishi Electric Research Laboratories (MERL). MERL is the North American research organisation of Mitsubishi Electric Corporation (Mitsubishi Electric Corporation, 2018). All the other organisations listed in Table 3 are universities or other public research institutions.

\begin{tabular}{ll}
\hline Organisation & Country \\
\hline 1. University of Salento & Italy \\
2. University of Brunswick - Institute of Technology & Germany \\
3. Seoul National University & South Korea \\
4. National University of Defense Technology & China \\
5. National Research Council & Italy \\
6. University of Oxford & England \\
7. Mitsubishi Electric Research Laboratories & USA \\
8. Hungarian Academy of Sciences & Hungary \\
9. Carnegie Mellon University & USA \\
\hline
\end{tabular}

Table 3: Top organisations by number of publications in research front (II) Driver Assistance Systems 
The most frequently cited article in research front (II) is also "Stanley: The Robot that won the DARPA Grand Challenge" by Thrun et al. (2006). The authors are affiliated with the University of Stanford and various companies in California. The fact that the paper by Thrun et al. (2006) also received the most citations in research front (I) underlines the similarity between these two research fronts.

The most cited publications of research front (II) appeared predominantly in the journals of the Institute of Electrical and Electronics Engineers (IEEE). The publication years range from 1988 to 2007. The most relevant article titled "Vision-based vehicles in Japan: machine vision systems and driving control systems" was published in the IEEE Transactions on Industrial Electronics in 1994. This paper is about three autonomously navigating vehicles developed between the mid1970 s and late 1980s. They were able to avoid obstacles and to drive autonomously between 10 and $50 \mathrm{~km} / \mathrm{h}$ (Tsugawa, 1994, p. 398). The latest highly cited article in research front (II) was published in 2007 in the Proceedings of the IEEE. The title is "Systems for safety and autonomous behavior in cars: The DARPA Grand Challenge experience". Finite state machines were developed to enable completely independent off-road driving. Attention was paid to the Grand Challenge competition, which is considered as the driver of such technologies (Özgüner et al., 2007, p. 397).

Overall, the article by Thrun et al. (2006) is by far the most important in research front (II), while all other publications assigned to research front (II) have a smaller impact. At journal level, the Journal of Field Robotics covers the most relevant articles. The journals of the Institute of Electrical and Electronics Engineers (IEEE) also provide relevant research results for driver assistance systems.

Regarding the affiliations of authors of articles assigned to research front (II), published work stems from all over the world. The aforementioned keywords can be confirmed by the highest cited publications, and they accordingly reflect the expected content. The reason is that before and after reviewing the subsequent work, all of them deal with moving machines that are supposed to rid humans of mechanical work and that can act independently and move around.

Table 4 lists the latest publications of research front (II) until 2017. The ten latest publications are from the years 2015 to 2017. The journals of the Institute of Electrical and Electronics Engineers (IEEE) contributed most of the latest publications. Research in this area took place predominantly in Asian countries, especially in South Korea.

\begin{tabular}{|c|c|c|c|c|}
\hline Author(s) & Title & Journal name & Publ. Year & Country \\
\hline $\begin{array}{l}\text { Jaakkola, Anttoni; et } \\
\text { al. }\end{array}$ & $\begin{array}{l}\text { Autonomous Collection of Forest Field } \\
\text { Reference - The Outlook and a First } \\
\text { Step with UAV Laser Scanning }\end{array}$ & Remote Sensing & 2017 & Finland \\
\hline Jang, C. H.; et al. & $\begin{array}{l}\text { Design factor optimization of 3D flash } \\
\text { lidar sensor based on geometrical } \\
\text { model for automated vehicle and } \\
\text { advanced driver assistance system } \\
\text { applications }\end{array}$ & $\begin{array}{c}\text { International Journal of Automotive } \\
\text { Technology }\end{array}$ & 2017 & $\begin{array}{l}\text { South } \\
\text { Korea }\end{array}$ \\
\hline $\begin{array}{l}\text { Son, Chang-Woo; } \\
\text { et al. }\end{array}$ & $\begin{array}{l}\text { MPC-based steering control for } \\
\text { backward-driving vehicle using stereo } \\
\text { vision }\end{array}$ & $\begin{array}{c}\text { International Journal of Automotive } \\
\text { Technology }\end{array}$ & 2017 & $\begin{array}{l}\text { South } \\
\text { Korea }\end{array}$ \\
\hline $\begin{array}{l}\text { Park, Myung Wook; } \\
\text { et al. }\end{array}$ & $\begin{array}{l}\text { Development of lateral control module } \\
\text { for zone (u-turn) maneuver of } \\
\text { vehicle/driver cooperative autonomous } \\
\text { driving system }\end{array}$ & $\begin{array}{c}\text { 2016 IEEE Transportation } \\
\text { Electrification Conference and } \\
\text { EXPO, Asia-Pacific (ITEC Asia- } \\
\text { Pacific) }\end{array}$ & 2016 & $\begin{array}{l}\text { South } \\
\text { Korea }\end{array}$ \\
\hline $\begin{array}{l}\text { Huang, WuLing; } \\
\text { et al. }\end{array}$ & $\begin{array}{l}\text { Autonomous vehicles testing methods } \\
\text { review }\end{array}$ & $\begin{array}{l}2016 \text { IEEE 19th International } \\
\text { Conference on Intelligent } \\
\text { Transportation Systems (ITSC) }\end{array}$ & 2016 & China \\
\hline $\begin{array}{l}\text { Berntorp, Karl; } \\
\text { Di Cairano, Stefano }\end{array}$ & $\begin{array}{l}\text { Particle filtering for online motion } \\
\text { planning with task specifications }\end{array}$ & $\begin{array}{l}2016 \text { American Control Conference } \\
\text { (ACC) }\end{array}$ & 2016 & USA \\
\hline $\begin{array}{l}\text { Kim, Minsung; } \\
\text { et al. }\end{array}$ & $\begin{array}{l}\text { Study on vehicle lateral control for } \\
\text { backward-driving }\end{array}$ & $\begin{array}{l}2016 \text { 13th International Conference } \\
\text { on Ubiquitous Robots and Ambient } \\
\text { Intelligence (URAI) }\end{array}$ & 2016 & $\begin{array}{l}\text { South } \\
\text { Korea }\end{array}$ \\
\hline
\end{tabular}


Sandra Boric, Edgar Schiebel, Christian Schlögl, Michaela Hildebrandt, Christina Hofer, Doris M. Macht

Research in Autonomous Driving - AHhistoric Bibliometric View of the Research Development in Autonomous Driving

\begin{tabular}{|c|c|c|c|c|}
\hline Author(s) & Title & Journal name & Publ. Year & Country \\
\hline $\begin{array}{l}\text { Pugeault, Nicolas; } \\
\text { Bowden, Richard }\end{array}$ & How much of driving is preattentive? & $\begin{array}{c}\text { IEEE Transactions on Vehicular } \\
\text { Technology } \\
\end{array}$ & 2015 & England \\
\hline $\begin{array}{l}\text { Broggi, Alberto; } \\
\text { et al. }\end{array}$ & $\begin{array}{l}\text { PROUD-Public road urban driverless- } \\
\text { car test }\end{array}$ & $\begin{array}{c}\text { IEEE Transactions on Intelligent } \\
\text { Transportation Systems }\end{array}$ & 2015 & Italy \\
\hline $\begin{array}{l}\text { Liu, Liming; } \\
\text { et al. }\end{array}$ & $\begin{array}{l}\text { A smart map representation for } \\
\text { autonomous vehicle navigation }\end{array}$ & $\begin{array}{c}2015 \text { 12th International Conference } \\
\text { on Fuzzy Systems and Knowledge } \\
\text { Discovery (FSKD) }\end{array}$ & 2015 & China \\
\hline
\end{tabular}

Table 4: Latest publications until 2017 in research front (II) Driver Assistance Systems

Many publications listed in Table 4 focus on technologies for environment detection in automated vehicles. The latest article "Autonomous collection of forest field reference - The Outlook and a first step with UAV laser scanning" deals with a method for the accurate and automatic collection of field data in forests. A mini-UVA laser scanning system was used to carry out the measurements by means of an unmanned aerial vehicle (UAV). This method is comparable to conventional terrestrial surveying scanners. This technique can be used to, e.g., generate more accurate map data in areas that are difficult to access (Jaakkola et al., 2017, p. 785). The second article in the list in Table 4 discusses the optimization possibilities of the 3D flash lidar, which is about increasing the readiness to operate using Advanced Driver Assistance Systems (ADAS) (Jang et al., 2017, p. 147). The third article on the list is "MPC-based steering control for backward-driving vehicle using stereo vision" and it discusses the used sensors in cars. It is about a control algorithm for autonomous backward-driving. When using a stereo camera, passable places should be detected more easily (Son et al., 2017, p. 933). The article "A smart map representation for autonomous vehicle navigation" is about a more accurate mapping of urban areas based on a Lidar map (Liu et al., 2015, p. 2308). The other articles listed in Table 4 explore the issues of steering (Kim et al., 2016; Park et al., 2016), predictions of traffic related events (Berntorp \& Di Cairano, 2016; Pugeault \& Bowden, 2015) and methods for testing used processes at different levels of automation (Broggi et al., 2015; Huang et al., 2016).

Compared to the highest cited publications in research front (I) which form the previously described knowledge base by cited references and which were more concerned with the holistic technology of automated vehicles, the latest research in research front (II) mainly deals with specific individual technologies. The technologies described are relevant for both ADAS and autonomous vehicles, since the technologies used in autonomous vehicles are based on ADAS.

\subsection{Research Front (III): Autonomous Mobile Robots}

The third research front (III) Autonomous Mobile Robots is, again, closely related to the research fronts (I) and (II) as autonomous driving also builds on the research results from autonomous mobile robots. The author keywords exhibit clearly the importance of autonomous and artificial intelligence in this research front. The keywords "mission accomplishment" and "dynamics control" can be mentioned here. The keyword "DGNSS" is the abbreviation for Differential Global Navigation Satellite System. The research on DGNSS is applied for more exact autonomous positioning measures employed by satellites (TransiTiva, 2018).

Table 5 shows that the most active university in research area (III) is located in Tokyo, Japan. According to the publications, German and US-American universities play a significant role in this research area, as well. Additionally, one company from Sweden was identified: Scania CV $A B$, a wholly owned subsidiary of Volkswagen AG (Scania CV AB, 2021).

\begin{tabular}{lll}
\hline \multicolumn{2}{l}{ Organisation } & Country \\
\hline 1. & University of Tokyo & Japan \\
2. & Technical University of Munich & Germany \\
\hline
\end{tabular}


Sandra Boric, Edgar Schiebel, Christian Schlögl, Michaela Hildebrandt, Christina Hofer, Doris M.

Macht

Research in Autonomous Driving - AHhistoric Bibliometric View of the Research Development in Autonomous Driving

\begin{tabular}{ll}
\hline Organisation & Country \\
\hline 3. Stanford University & USA \\
4. Scania CV AB & Sweden \\
5. Chalmers University of Technology & Sweden \\
6. Carnegie Mellon University & USA \\
7. Beijing Institute of Technology & China \\
\hline
\end{tabular}

Table 5: Top organisations by number of publications in research front (III) Autonomous Mobile Robots

The three most frequently cited items were all published in the Journal of Field Robotics in 2008. All three publications describe robot cars and the technology used at the DARPA Urban Challenge. The by far highest cited article - which is also included in research front (I) - is "Junior: The Stanford Entry in the Urban Challenge" by Montemerlo et al. (2008). It appeared in the same journal issue as the article "Little Ben: The Ben Franklin Racing Team's entry in the 2007 DARPA Urban Challenge" by Bohren et al. (2008). The latter article deals with the autonomous land vehicle Little Ben which was constructed by the Ben Franklin Racing Team for the DARPA Urban Challenge 2007 for less than $\$ 250,000$. It describes the capture, planning, navigation, and actuation systems developed for Little Ben. Little Ben was one of six cars which successfully finished the Urban Challenge (Bohren et al., 2008, p. 598). The article by Bacha et al. (2008) titled "Odin: Team VictorTango's Entry in the DARPA Urban Challenge" describes how the VictorTango team built the Odin robot car based on a Ford Escape. This paper captures the used technology, the performance of these components in the Urban Challenge, and their successes. Odin successfully finished the Urban Challenge and ranked third (Bacha et al., 2008, pp. 467-468). Another relevant article was published in the IEEE Transactions on Control Systems Technology in the year 2007. It introduced the model predictive control (MPC) for controlling an active front steering system in an autonomous vehicle (Falcone et al., 2007, p. 566).

Table 6 lists the ten latest publications assigned to research front (III) which are all published between 2014 and $2017^{2}$. It is noticeable that half of these publications have been published in journals or proceedings of the Institute of Electrical and Electronics Engineers (IEEE). Research in this area took place in predominantly Asian countries, especially in China, but also in some European countries such as Germany and Sweden.

\begin{tabular}{|c|c|c|c|c|}
\hline Author(s) & Title & Journal name & Publ. Year & Country \\
\hline $\begin{array}{l}\text { Hu, Xuemin; } \\
\text { et al. }\end{array}$ & $\begin{array}{l}\text { Dynamic path planning for autonomous } \\
\text { driving on various roads with avoidance of } \\
\text { static and moving obstacles }\end{array}$ & $\begin{array}{l}\text { Mechanical Systems and } \\
\text { Signal Processing }\end{array}$ & 2018 & $\begin{array}{l}\text { China, } \\
\text { USA }\end{array}$ \\
\hline $\begin{array}{l}\text { Ni, Jun; } \\
\text { et al. }\end{array}$ & $\begin{array}{l}\text { Envelope control for four-wheel independently } \\
\text { actuated autonomous ground vehicle through } \\
\text { AFS/DYC integrated control }\end{array}$ & $\begin{array}{l}\text { IEEE Transactions on } \\
\text { Vehicular Technology }\end{array}$ & 2017 & China \\
\hline $\begin{array}{l}\text { Ni, Jun; } \\
\text { Hu, Jibin }\end{array}$ & $\begin{array}{l}\text { Dynamic control of autonomous vehicle at } \\
\text { driving limits and experiment on an } \\
\text { autonomous formula racing car }\end{array}$ & $\begin{array}{l}\text { Mechanical Systems and } \\
\text { Signal Processing }\end{array}$ & 2017 & China \\
\hline $\begin{array}{l}\text { Lenz, David; } \\
\text { et al. }\end{array}$ & $\begin{array}{l}\text { Tactical cooperative planning for autonomous } \\
\text { highway driving using Monte-Carlo tree search }\end{array}$ & $\begin{array}{c}2016 \text { IEEE Intelligent } \\
\text { Vehicles Symposium (IV) }\end{array}$ & 2016 & Germany \\
\hline $\begin{array}{l}\text { Hsu, Li-Ta; } \\
\text { et al. }\end{array}$ & $\begin{array}{l}\text { Autonomous driving positioning using } \\
\text { building model and DGNSS }\end{array}$ & $\begin{array}{l}2016 \text { European Navigation } \\
\text { Conference (ENC) }\end{array}$ & 2016 & Japan \\
\hline $\begin{array}{l}\text { Lima, Pedro F.; } \\
\text { et al. }\end{array}$ & $\begin{array}{l}\text { Clothoid-based speed profiler and control for } \\
\text { autonomous driving }\end{array}$ & $\begin{array}{l}2015 \text { IEEE } 18 \text { th International } \\
\text { Conference on Intelligent } \\
\text { Transportation Systems }\end{array}$ & 2015 & Sweden \\
\hline
\end{tabular}

\footnotetext{
${ }^{2}$ One article published in 2018 was already available in electronic form at the time of data retrieval in 2017.
} 
Sandra Boric, Edgar Schiebel, Christian Schlögl, Michaela Hildebrandt, Christina Hofer, Doris M. Macht

Research in Autonomous Driving - AHhistoric Bibliometric View of the Research Development in Autonomous Driving

\begin{tabular}{|c|c|c|c|c|}
\hline Author(s) & Title & Journal name & Publ. Year & Country \\
\hline $\begin{array}{l}\text { Gu, Tianyu; } \\
\text { et al. }\end{array}$ & $\begin{array}{l}\text { Tunable and stable real-time trajectory } \\
\text { planning for urban autonomous driving }\end{array}$ & $\begin{array}{c}2015 \text { IEEE/RSJ International } \\
\text { Conference on Intelligent } \\
\text { Robots and Systems (IROS) }\end{array}$ & 2015 & USA \\
\hline $\begin{array}{l}\text { Hsu, Li-Ta; } \\
\text { et al. }\end{array}$ & $\begin{array}{l}\text { Rectification of 3D building models based on } \\
\text { GPS signal collected by vehicle }\end{array}$ & $\begin{array}{c}2015 \text { IEEE International } \\
\text { Conference on Vehicular } \\
\text { Electronics and Safety } \\
\text { (ICVES) }\end{array}$ & 2015 & Japan \\
\hline $\begin{array}{l}\text { Matthaei, Richard; } \\
\text { Maurer, Markus }\end{array}$ & Autonomous driving - a top-down-approach & AT-Automatisierungstechnik & 2015 & Germany \\
\hline $\begin{array}{l}\text { Drage, } \\
\text { Thomas H.; } \\
\text { et al. }\end{array}$ & $\begin{array}{l}\text { Development of an autonomous formula SAE } \\
\text { car with laser scanner and GPS }\end{array}$ & IFAC PapersOnLine & 2014 & Australia \\
\hline
\end{tabular}

Table 6: Latest publications until 2017 (2018) in research front (III) Autonomous Mobile Robots

The latest publications listed in Table 6 describe planning and control systems of autonomous mobile robots. For example, the article "Dynamic path planning for autonomous driving on various roads with Avoidance of Static and Moving Obstacles" discusses a real-time path planning procedure designed to avoid obstacles (Hu et al., 2018, p. 482). Another publication examines real-time motion planning for cities (Gu et al., 2015, p. 250). The article "Envelope control four-wheel independently actuated autonomous around vehicles through AFS/DYC integrated control" deals with an envelope control frame for a four-wheel drive vehicle ( $\mathrm{Ni}$ et al., 2017, p. 9712). Another article also deals with a dynamic controller that aims to help improving the longitudinal and lateral steering of a vehicle ( $\mathrm{Ni} \& \mathrm{Hu}, 2017, \mathrm{p} .154$ ). The development of a control system for autonomous racing cars is described in the paper by (Drage et al., 2014, p. 2652). The other articles are about localization and mapping (Hsu et al., 2016), predicting the intentions of other road users (Lenz et al., 2016), and speed (Lima et al., 2015).

Compared to the highest cited publications previously described which concentrated on vehicles of the DARPA challenges, the latest research activities are moving towards specific individual technical solutions for autonomous driving.

\subsection{Research Front (IV): IntraFace}

The fourth identified research front consists of five publications which are all about IntraFace. IntraFace is a software package for automated facial feature tracking, head pose estimation, facial attribute recognition, and facial expression analysis from video. It has been developed by scientists from the Technical University of Pittsburgh, which was already mentioned in research front (I). Researchers in that field are working on the development of algorithms for automatic face analysis. This software enables an automatic identification, tracking, and interpretation of facial expressions and associated emotions. Since autonomous driving requires new forms of user interaction, further developments and applications for autonomous driving can be expected from IntraFaces. IntraFace should therefore play a prominent role in the research for autonomous driving systems in the near future (Torre et al., 2017, p. 1).

\section{Summary}

This article's goal was to show the use of bibliometric methods in order to picture the development of the research area of autonomous driving. For this purpose, we analysed the research literature on autonomous driving by mapping it via the bibliometric software BibTechMon. Science mapping is a bibliometric method that enables a structuring of disciplines, scientific domains, and/or research fronts of a research area. Science mapping can be performed in various ways. In our analysis, we used bibliographic coupling according to which there is a 
similarity between documents if they have at least one reference in common. The more identical references articles have in common, the stronger their relation. On this basis, it is possible to identify and visualise the main research fronts of a research topic - in our case of autonomous driving.

To visualize the time distribution of research, a total of 1,445 publications that included the phrase "autonomous driving" either in the title, keyword, or abstract fields, and which were published between 2000 and 2017 were retrieved from the Web of Science (WoS) database. The time distribution analysis shows that there is a strong increase in the number of publications between 2013 and 2017. This indicates that autonomous driving had become an emerging research topic in 2017.

Using the bibliometric software BibTechMon as well as 1,202 publications published between 2010 and 2017, four major and partially closely related research fronts were identified: (I) Autonomous Vehicles and Infrastructure, (II) Driver Assistance Systems, (III) Autonomous Mobile Robots, and (IV) IntraFace.

Research front (I) was found to be more general and, consequently, the largest research front with approximately 100 publications. It deals mainly with the development of autonomous vehicles, their software, and the necessary infrastructure. The fact that nearly all of the toppublishing organisations in research front (I) are university departments suggests that the related research is still at an early development stage.

Research front (II) is second largest research front, dealing with driver assistance systems. This is expressed by keywords such as "backward driving" and "self-learning classifier". Most of the publications in research front (II) focus on technologies for environment detection in automated vehicles, steering, and the prediction of traffic related events.

Just like research front (II), research front (III) is also closely connected to research front (I). Robots and artificial intelligence play a key role in the publications assigned to this research front. This is evident by the three most frequently cited articles in research front (III) being published in the Journal of Field Robotics. Many of the most recent publications in research front (III) deal with planning and control systems of autonomous mobile robots, with localization and mapping, and with predicting the intentions of other road users.

Research front (IV) covers IntraFace and is by far the smallest and most specific of the four identified research fronts. It contains publications that describe the development of algorithms for automatic facial analysis. The IntraFace software enables an automatic identification, tracking, and interpretation of facial expressions and associated emotions to interact with the artificial intelligence of an autonomously driving car.

As our performed analyses and results exhibit, science mapping is a method that enables an identification of currently emerging research topics. However, it should be noted that the labelling of research fronts nevertheless remains mainly an intellectual task that must be performed by a human being who analyses papers of various research fronts. In the ideal case, the labelling is performed by experts of the to-be-analysed research field.

One major shortcoming of our study is that the analyses were conducted in the year 2017. For topics for which research is being conducted at a rapid pace - such as is the case for autonomous driving - a regular update of such bibliometric analyses is necessary. Therefore, we plan to perform another such bibliometric analysis of autonomous driving in the near future.

\section{References}

- Ahlgren, P., \& Jarneving, B. (2008). Bibliographic coupling, common abstract stems and clustering: A comparison of two document-document similarity approaches in the context of science mapping. Scientometrics, 76(2), 273-290. CrossRef 
- AIT Austrian Institute of Technology GmbH. (2018). BibTechMon - A software tool for bibliometric technology monitoring.

- Bacha, A., Bauman, C., Faruque, R., Fleming, M., \& Terwelp, C. (2008). Odin: Team VictorTango's Entry in the DARPA Urban Challenge. Journal of Field Robotics 25(8), 25(8), 467-492. CrossRef

- Bardt, H. (2016). Deutsche Autoindustrie und autonomes Fahren. Wirtschaftsdienst, 96(10), 776-778. CrossRef

- Barthelmes, S., Czeh, A., Guo, Y., \& Landfester, Gunnar Lönne, Johannes Schumann, T. (2017). Autonomes Fahren. Erwartungen an die Mobilität der Zukunft. In Autonomes Fahren. Erwartungen an die Mobilität der Zukunft.

- Berntorp, K., \& Di Cairano, S. (2016). Particle filtering for online motion planning with task specifications. Proceedings of the American Control Conference, 2016-July, 21232128.

- BMVI - Automatisiertes und vernetztes Fahren. (n.d.).

- Bohren, J., Foote, T., Keller, J., Kushleyev, A., Lee, D., Stewart, A., Vernaza, P., Derenick, J., Spletzer, J., \& Satterfield, B. (2008). Little Ben: The Ben Franklin Racing Team's entry in the 2007 DARPA Urban Challenge. Journal of Field Robotics, 25, 598614. CrossRef

- Börner, K., Theriault, T. N., \& Boyack, K. W. (2015). Mapping science introduction: Past, present and future. Bulletin of the Association for Information Science and Technology, $41(2), 12-16$.

- Broggi, A., Cerri, P., Debattisti, S., Laghi, M. C., Medici, P., Molinari, D., Panciroli, M., \& Prioletti, A. (2015). PROUD-Public Road Urban Driverless-Car Test. IEEE Transactions on Intelligent Transportation Systems, 16(6), 3508-3519.

- Brownsword, R., Scotford, E., \& Yeung, K. (2017). The Oxford Handbook of Law, Regulation and Technology. OUP Oxford.

- Cacilo, A., Schmidt, S., Wittlinger, P., Herrmann, F., Bauer, W., Sawade, O., Doderer, H., Hartwig, M., \& Scholz, V. (2015). Hochautomatisiertes Fahren auf Autobahnen-Industriepolitische Schlussfolgerungen. Stuttgart: Fraunhofer-Institut Für Arbeitswirtschaft Und Organisation IAO.

- Callon, M., Courtial, J.-P., Turner, W. A., \& Bauin, S. (1983). From translations to problematic networks: An introduction to co-word analysis. Social Science Information, 22(2), 191-235. CrossRef

- Cao, P., Hu, Y., Miwa, T., Wakita, Y., Morikawa, T., \& Liu, X. (2017). An optimal mandatory lane change decision model for autonomous vehicles in urban arterials. Journal of Intelligent Transportation Systems, 21(4), 271-284. CrossRef

- Chen, X., Chen, J., Wu, D., Xie, Y., \& Li, J. (2016). Mapping the Research Trends by Coword Analysis Based on Keywords from Funded Project. Procedia Computer Science, 91, 547-555.

- Cobo, M. J., López-Herrera, A. G., Herrera-Viedma, E., \& Herrera, F. (2011). Science mapping software tools: Review, analysis, and cooperative study among tools. Journal of the American Society for Information Science and Technology, 62(7), 1382-1402.

- Daimler. (2021). Daimler: Company History - Benz Patent Motor Car: The first automobile (1885 - 1886).

- Darweesh, H., Takeuchi, E., Takeda, K., Ninomiya, Y., Sujiwo, A., Morales, L. Y., Akai, N., Tomizawa, T., \& Kato, S. (2017). Open Source Integrated Planner for Autonomous Navigation in Highly Dynamic Environments. Journal of Robotics and Mechatronics, 29(4), 668-684. CrossRef

- De Lange, C., \& Glänzel, W. (1997). Modelling and measuring multilateral co-authorship in international scientific collaboration. Part I. Development of a new model using a series expansion approach. Scientometrics, 40(3), 593-604. CrossRef

- Drage, T. H., Kalinowski, J., \& Bräunl, T. (2014). Development of an autonomous formula SAE car with laser scanner and GPS. In IFAC Proceedings Volumes (IFACPapersOnline) (Vol. 19, Issue 3). IFAC.

- Falcone, P., Borrelli, F., Asgari, J., Tseng, H. E., \& Hrovat, D. (2007). Predictive Steering Control for Autonomous Vehicle Systems. IEEE Transactions on Control Systems Technology, 15(3), 566-580.

- Feil, E. (1987). Antithetik neuzeitlicher Vernunft: "Autonomie-Heteronomie" und "rational-irrational." Vandenhoeck \& Ruprecht. CrossRef

- Fischler, M. A., \& Bolles, R. C. (1981). Random sample consensus: a paradigm for model fitting with applications to image analysis and automated cartography. Communications of the ACM, 24(6), 381-395. 
- Fraedrich, E., Berlin, H., \& Lenz, B. (2014). Autonomes Fahren - Mobilität und Auto in der Welt von morgen. Ausblick zur Akzeptanz des autonomen Fahrens im Projekt "Villa Ladenburg" der Daimler und Benz Stiftung. Technikfolgenabschätzung - Theorie Und Praxis, 23(1), 46-53. CrossRef

- Galceran, E., Cunningham, A. G., Eustice, R. M., \& Olson, E. (2017). Multipolicy decision-making for autonomous driving via changepoint-based behavior prediction: Theory and experiment. Autonomous Robots, 41(6), 1367-1382.

- Gasser, T., Arzt, C., \& Ayoubi, M. (2012). Rechtsfolgen zunehmender Fahrzeugautomatisierung. In Berichte der Bundesanstalt für Straßenwesen, Unterreihe "Fahrzeugsicherheit" Heft F83, Januar 2012.

- Gu, T., Atwood, J., Dong, C., Dolan, J. M., \& Lee, J. W. (2015). Tunable and stable realtime trajectory planning for urban autonomous driving. IEEE International Conference on Intelligent Robots and Systems, 12, 250-256. CrossRef

- Gwon, G.-P., Hur, W.-S., Kim, S.-W., \& Seo, S.-W. (2017). Generation of a Precise and Efficient Lane-Level Road Map for Intelligent Vehicle Systems. IEEE Transactions on Vehicular Technology, 66(6), 4517-4533.

- Handelsblatt. (2018, March 19). Fussgängerin erfasst. Uber War Laut Ersten Ermittlungen Nicht Schuld an Tödlichem Unfall Mit Roboterfahrzeug.

- Hsu, L.-T., Gu, Y., \& Kamijo, S. (2016). Autonomous Driving Positioning using Building Model and DGNSS. 2016 European Navigation Conference (ENC), 1-7.

- Hu, X., Chen, L., Tang, B., Cao, D., \& He, H. (2018). Dynamic path planning for autonomous driving on various roads with avoidance of static and moving obstacles. Mechanical Systems and Signal Processing, 100, 482-500.

- Huang, R., Liang, H., Zhao, P., Yu, B., \& Geng, X. (2017). Intent-Estimation- and Motion-Model-Based Collision Avoidance Method for Autonomous Vehicles in Urban Environments. Applied Sciences, 7(5), 457.

- Huang, W., Kunfeng Wang, Yisheng LV, \& FengHua Zhu. (2016). Autonomous vehicles testing methods review. 2016 IEEE 19th International Conference on Intelligent Transportation Systems (ITSC), 163-168.

- Jaakkola, A., Hyyppä, J., Yu, X., Kukko, A., Kaartinen, H., Liang, X., Hyyppä, H., \& Wang, Y. (2017). Autonomous collection of forest field reference-The outlook and a first step with UAV laser scanning. Remote Sensing, 9(8), 785.

- Jang, C. H., Kim, C. S., Jo, K. C., \& Sunwoo, M. (2017). Design factor optimization of 3D flash lidar sensor based on geometrical model for automated vehicle and advanced driver assistance system applications. International Journal of Automotive Technology, $18(1), 147-156$.

- Jo, K., Lee, M., Kim, C., \& Sunwoo, M. (2017). Construction process of a threedimensional roadway geometry map for autonomous driving. Proceedings of the Institution of Mechanical Engineers, Part D: Journal of Automobile Engineering, 231(10), 1414-1434.

- Kessler, M. M. (1963). Bibliographic coupling between scientific papers. American Documentation, 14(1), 10-25. CrossRef

- Kim, M., Shin, S., \& Park, J. (2016). Study on vehicle lateral control for backward driving. 2016 13th International Conference on Ubiquitous Robots and Ambient Intelligence (URAI), 191-193.

- Kopcsa, A., \& Schiebel, E. (1998). Science and Technology Mapping - A New Iteration Model for Representing Multidimensional Relationships. Journal of the American Society for Information Science and Technology, 49(1), 7-17. https://doi.org/10.1002/(SICI)1097-4571(1998)49:13.0.CO;2-W

- Krieger-Lamina, J. (2016). Vernetzte Automobile - Datensammeln beim Fahren: von Assistenzsystemen zu autonomen Fahrzeugen (p. 89). Austrian Academy of Sciences.

- Krimmel, H., \& Ersoy, M. (2017). Fahrwerkelektronik. In Fahrwerkhandbuch (pp. 747792). Springer Fachmedien Wiesbaden. https://doi.org/10.1007/978-3-658-154684_15

- Krystek, U. (2007). Strategische Früherkennung. Controlling \& Management, 51(S2), 50-59. CrossRef

- Kyriakidis, M., Happee, R., \& de Winter, J. C. F. (2015). Public opinion on automated driving: Results of an international questionnaire among 5000 respondents. Transportation Research Part F: Traffic Psychology and Behaviour, 32, 127-140. CrossRef

- Langheim, J. (2015). Energy Consumption and Autonomous Driving: Proceedings of the 3rd CESA Automotive Electronics Congress, Paris, 2014 (Jochen Langheim (Ed.)). 
Springer International Publishing.

- $\quad$ Lenz, D., Kessler, T., \& Knoll, A. (2016). Tactical Cooperative Planning for Autonomous Vehicles using MCTS. IEEE Intelligent Vehicles Symposium, IV, 1-7.

- Levinson, J., Askeland, J., Becker, J., Dolson, J., Held, D., Kammel, S., Kolter, J. Z., Langer, D., Pink, O., Pratt, V., Sokolsky, M., Stanek, G., Stavens, D., Teichman, A., Werling, M., \& Thrun, S. (2011). Towards fully autonomous driving: Systems and algorithms. IEEE Intelligent Vehicles Symposium, Proceedings, 163-168. CrossRef

- Lietz, H. (2013). Diagnose von Emerging Science. Die Fälle "New Science of Networks" und Szientometrie. In H. P. Ohly (Ed.), Wissen - Wissenschaft - Organisation. (1st ed., p. 408). Ergon-Verlag.

- Lima, P. F., Trincavelli, M., Martensson, J., \& Wahlberg, B. (2015). Clothoid-Based Speed Profiler and Control for Autonomous Driving. 2015 IEEE 18th International Conference on Intelligent Transportation Systems, 2015-Novem, 2194-2199. CrossRef

- Liu, L., Wu, T., Fang, Y., Hu, T., \& Song, J. (2015). A smart map representation for autonomous vehicle navigation. 2015 12th International Conference on Fuzzy Systems and Knowledge Discovery, FSKD 2015, 2308-2313.

- Matthaei, R., Reschka, A., Rieken, J., Dierkes, F., Ulbrich, S., Winkle, T., \& Maurer, M. (2015). Automomes Fahren. In H. Winner, S. Hakuli, F. Lotz, \& C. Singer (Eds.), Handbuch Fahrerassistenzsysteme: Grundlagen, Komponenten und Systeme für aktive Sicherheit und Komfort (3rd ed., pp. 1139-1166). Springer Fachmedien Wiesbaden.

- Maurer, M., Gerdes, J. C., Lenz, B., \& Winner, H. (2015). Autonomes Fahren: Technische, rechtliche und gesellschaftliche Aspekte. Springer Berlin Heidelberg. CrossRef

- Mitsubishi Electric Corporation. (2018). R\&D centers: Mitsubishi Electric Research Laboratories (MERL).

- Montemerlo, M., Becker, J., Bhat, S., Dahlkamp, H., Dolgov, D., Ettinger, S., Haehnel, D., Hilden, T., Hoffmann, G., Huhnke, B., Johnston, D., Klumpp, S., Langer, D., Levandowski, A., Levinson, J., Marcil, J., Orenstein, D., Paefgen, J., Penny, I., ... Thrun, S. (2008). Junior: The Stanford entry in the Urban Challenge. Journal of Field Robotics, 25(9), 569-597.

- $\quad \mathrm{Ni}$, J., \& Hu, J. (2017). Dynamics control of autonomous vehicle at driving limits and experiment on an autonomous formula racing car. Mechanical Systems and Signal Processing, 90, 154-174.

- $\quad \mathrm{Ni}$, J., Hu, J., \& Xiang, C. (2017). Envelope Control for Four-Wheel Independently Actuated Autonomous Ground Vehicle Through AFS/DYC Integrated Control. IEEE Transactions on Vehicular Technology, 66(11), 9712-9726. CrossRef

- Özgüner, Ü., Stiller, C., \& Redmill, K. (2007). Systems for safety and autonomous behavior in cars: The DARPA grand challenge experience. Proceedings of the IEEE, 95(2), 397-412.

- Park, M. W., Lee, S. H., \& Han, W. (2016). Development of lateral control module for zone(u-turn) maneuver of vehicle/driver cooperative autonomous driving system. 2016 IEEE Transportation Electrification Conference and Expo, Asia-Pacific (ITEC Asia-Pacific), 908-912.

- Price, D. J. D. S. (1965). Networks of Scientific Papers. Science, 149(3683), 510-515.

- Pugeault, N., \& Bowden, R. (2015). How much of driving is preattentive? IEEE Transactions on Vehicular Technology, 64(12), 5424-5438. CrossRef

- Scania CV AB. (2021). Scania - Homepage. Company History.

- Schreurs, M. A., \& Steuwer, S. D. (2016). Autonomous driving-political, legal, social, and sustainability dimensions. In Autonomous Driving: Technical, Legal and Social Aspects (pp. 149-171). CrossRef

- Schuh, G., Klappert, S., \& Moll, T. (2010). Ordnungsrahmen Technologiemanagement. In Technologiemanagement (pp. 11-31). Springer Berlin Heidelberg. $\mathrm{h}$

- Son, C.-W., Choi, W., \& Ahn, C. (2017). MPC-BASED steering control for backwarddriving vehicle using stereo vision. International Journal of Automotive Technology, 5, 933-942.

- Thrun, S., Montemerlo, M., Dahlkamp, H., Stavens, D., Aron, A., Diebel, J., Fong, P., Gale, J., Halpenny, M., Hoffmann, G., Lau, K., Oakley, C., Palatucci, M., Pratt, V., Stang, P., Strohband, S., Dupont, C., Jendrossek, L.-E., Koelen, C., ... Mahoney, P. (2006). Stanley: The robot that won the DARPA Grand Challenge. Journal of Field Robotics, 23(9), 661-692.

- Torre, De la, F., Chu, W.-S., Xiong, X., Vicente, F., Ding, X., \& Cohn, J. (2017). Intraface. 
- TransiTiva. (2018). What is Differential GPS/GNSS? CrossRef

- Tsugawa, S. (1994). Vision-Based Vehicles in Japan: Machine Vision Systems and Driving Control Systems. IEEE Transactions on Industrial Electronics, 41(4), 398-405. CrossRef

- Urmson, C., Anhalt, J., Bagnell, D., Baker, C., Bittner, R., Clark, M. N., Dolan, J., Duggins, D., Galatali, T., Geyer, C., Gittleman, M., Harbaugh, S., Hebert, M., Howard, T. M., Kolski, S., Kelly, A., Likhachev, M., McNaughton, M., Miller, N., ... Ferguson, D. (2008). Autonomous driving in urban environments: Boss and the Urban Challenge. Journal of Field Robotics, 25(8), 425-466. CrossRef

- Watzenig, D, \& Horn, M. (2016). Automated Driving: Safer and More Efficient Future Driving (Daniel Watzenig \& H. Martin (Eds.); 1st ed.). Springer International Publishing. CrossRef

- Wellensiek, M., Schuh, G., Hacker, P. A., \& Saxler, J. (2010). Technologiefrüherkennung. In Technologiemanagement (pp. 89-169). Springer Berlin Heidelberg. CrossRef

- Yin, H., Yang, X., \& He, C. (2016). Spherical Coordinates Based Methods of Ground Extraction and Objects Segmentation Using 3-D LiDAR Sensor. IEEE Intelligent Transportation Systems Magazine, 8(1), 61-68. CrossRef

- Ziegler, J., Bender, P., Schreiber, M., \& others. (2014). Making Bertha Drive - An Autonomous Journey on a Historic Route. Intelligent Transportation Systems Magazine, 6(2), 8-20. CrossRef 